\title{
Acetone, a Sustainable Solvent for Electrospinning Poly( $\varepsilon$-Caprolactone) Fibres: Effect of Varying Parameters and Solution Concentrations on Fibre Diameter
}

\author{
Lucy A. Bosworth - Sandra Downes
}

(C) Springer Science+Business Media, LLC 2012

\begin{abstract}
Electrospinning commonly requires a solvent carrier to transform polymer materials from one solid form to another. The types of solvents are often classed as toxic and hazardous and have potential long-term impacts on the environment and the health of the user. Acetone is a sustainable and non-toxic solvent, but has received limited use within the electrospinning sector-particularly for biocompatible polymers, such as poly( $\varepsilon$-caprolactone) (PCL). This paper documents the ability to electrospin PCL dissolved in acetone and the effects of spinning parameters on the morphology and diameter of the collected fibres. Depending on the end use of the collected fibres it is important to understand how the parameters interplay and affect fibre morphology and diameter, especially if fibres of a specific form and size are required, for example, to mimic the extracellular matrix of tissues. This paper investigates the effects of flow-rate $(0.05$ and $0.1 \mathrm{ml} / \mathrm{min})$, voltage $(15$ and $25 \mathrm{kV})$, distance $(5$ and $10 \mathrm{~cm})$ and voltage-distance combined, on different concentrations of poly( $\varepsilon$-caprolactone)/acetone solutions $(5,7.5$ and $10 \% \mathrm{w} / \mathrm{v})$ in terms of fibre morphology and fibre diameter. Overall, solutions of PCL dissolved in acetone could be electrospun and, in general, the trends observed with altering spinning parameters followed those documented for other polymer/ solvent systems. This calls for the increased use of less hazardous and more sustainable solvents, such as acetone, for electrospinning applications.
\end{abstract}

L. A. Bosworth $(\bowtie) \cdot S$. Downes

Materials Science Centre, The University of Manchester,

Grosvenor Street, Manchester M1 7HS, UK

e-mail: lucy.bosworth@manchester.ac.uk
Keywords Electrospinning - Poly( $\varepsilon$-caprolactone) (PCL) . Acetone $\cdot$ Sustainability $\cdot$ Fibres $\cdot$ Parameters .

Solution concentration

\section{Introduction}

The electrospinning process utilises high voltages to generate internal repulsive forces within a polymer solution. At a critical point these forces cause the expulsion of the polymer solution in the form of fine diameter fibres, for example; Zhou et al. [1] fabricated electrospun fibres of polyaniline/polyethylene oxide with diameters of approximately $5 \mathrm{~nm}$.

In brief, a high voltage power supply is connected to a needle-tipped syringe containing a polymeric solution with an applied flow rate (Fig. 1). The earthed, target collector is positioned at a known distance from the needle-tip. Application of a sufficiently high voltage causes the polymeric solution to charge and formation of a Taylor cone is observed [2]. Expulsion of the polymer as a charged jet occurs once the charge intensity of the solution is sufficient to overcome the surface tension and visco-elastic forces of this Taylor cone [3]. The electric potential draws the charged polymer jet across an air gap and due to solvent evaporation and charge repulsion, the jet stretches and thins as it travels towards the collector. Upon impact with the collector the charge of the fibres dissipates and the electrical circuit is completed.

As mentioned, the standard electrospinning setup incorporates the use of solvents to act as carriers during the formation of polymer fibres-the solvent aids the transition of the polymer from one form (e.g. solid pellets) to another (e.g. fibres). The literature documents a wide range of polymer/solvent systems to enable this transition [4-6]; 


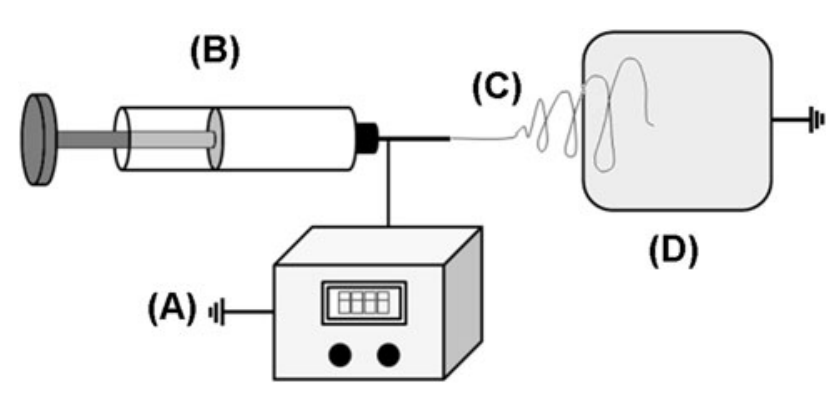

Fig. 1 Schematic of the electrospinning process. Where (a) is a high voltage supply connected to the needle of the syringe (b) containing the polymer solution. Application of a voltage causes expulsion of the polymer in the form of fibres (c) that are collected on the earthed target $(\mathbf{d})$

however, there is little focus on the sustainability and environmental impact of these solvents. Whilst it could be argued there is no implication as the solvent is fully evaporated during the electrospinning process, it needs to be remembered that users are still exposed to these solvents when making the polymer/solvent solutions and during the electrospinning process. Consequently, the exposure of users to these solvents, particularly over long electrospinning periods and during mass production, could have a long lasting and detrimental impact on their health. Hence the use of non-toxic and fairly innocuous solvents, such as acetone, should to be utilised to a greater degree $[7,8]$. In addition, acetone can be produced via biotechnological processes, which makes its manufacture highly sustainable $[9,10]$.

In recent years, electrospinning has found multiple uses in a number of different research areas, including; biomaterials and tissue engineering [11, 12], filtration [13, 14] and energy $[15,16]$. Specifically within the biomaterials and tissue engineering field, it is vital that the scaffold structure mimics the tissue it is intended to replace as closely as possible otherwise failure of the device is likely to occur. Electrospinning is a technique capable of producing nanofibrous structures with diameters and composition comparable to the ultra-structure of many tissues [17]. With this in mind it is important that the researcher determines the ideal spinning parameters for fabricating fibres that replicate the natural tissue. Consequently, time must be spent investigating the different parameters and their subsequent permutations. There are many parameters, which can be subdivided as follows;

1. Electrospinning set-up-applied voltage, flow-rate, needle-tip to collector distance.

2. Polymeric solution properties-concentration, viscosity, surface tension, conductivity, molecular weight.

3. Ambient conditions-external temperature and humidity, local air velocity.
Further details regarding these parameters have been discussed previously [18].

A number of biopolymers have been electrospun for a wide range of potential medical device applications, such as poly(lactic-co-glycolic acid) (PLGA) for heart tissue constructs and poly(L-lactic acid) (PLLA) for bone regeneration $[19,20]$. Another commonly used biopolymer, poly( $\varepsilon$-caprolactone) (PCL), has been electrospun by a number of research groups investigating nerve repair [21, $22]$, tendon regeneration [23, 24] and tissue engineering of skin $[25,26]$. However, the solvent systems used between research groups varies; for example, PCL can be electrospun with a number of solvents including, dichloromethane (DCM) [27], trifluoroethanol (TFE) [28] and hexafluoro-2propanol (HFP) [29]. Consequently the electrospinning parameters required to repeatedly fabricate fibres of appropriate dimensions and morphologies will vary from one solvent system to another because of the variability in conductivity, surface tension and dielectric constant between solvents.

Whilst effects of solvents and parameter studies have been conducted previously [30, 31], no such study has been conducted for a more sustainable and less hazardous polymer solvent system, such as PCL and acetone. Consequently, this paper aims to investigate the ability to electrospin PCL dissolved in acetone and how the morphology and diameter of collected PCL fibres is affected by solution concentration and electrospinning parameterssolution flow-rate, applied voltage, distance between the needle-tip and collector and combination of varying both voltage and distance simultaneously.

\section{Materials and Methods}

Optimising Polymer Solution Properties and Electrospinning Parameters

In order to ascertain the ideal spinning parameters for producing submicron fibres from poly( $\varepsilon$-caprolactone) (PCL) $\left(\mathrm{M}_{n} 80\right.$ 000; Sigma Aldrich) dissolved in acetone (Fisher Scientific) a range of variables were selected and tested. An earthed stationary plate was used to collect emitted polymer fibres. To allow for an evenly formed droplet at the end of the needle-tip, all needles ( $21 \mathrm{~g}, \varnothing$ $0.8 \mathrm{~mm}$; BD Microlance) had the tip removed and the edge smoothed before use.

The selected parameters were chosen because each is known to have an effect on the fibre outcome, and are listed as follows:

- Concentration of polymer-solvent solution

- Applied voltage 
- Tip to collector distance

- Flow rate of polymer-solvent solution

\section{Concentration of Polymer Solvent Solution}

Solution concentrations investigated were 5, 7.5 and $10 \% \mathrm{w} / \mathrm{v}$ respectively. Polymeric solutions were prepared by weighing out a known quantity of PCL into a glass jar together with a known volume of acetone. Glass jars were air-tight and placed on a heated stirrer $\left(40{ }^{\circ} \mathrm{C}\right)$ until the polymer dissolved.

\section{Applied Voltage}

The electrospinning process was performed using two separate voltages -15 and $25 \mathrm{kV}$. The voltage was preset to the correct value prior to the start of electrospinning. Voltage was supplied by FC Series 120 Watt regulated high voltage DC power supply from Glassman High Voltage, Inc.

\section{Needle-Tip to Collector Distance}

The needle-tip to collector distance is the length between the tip of the needle to the collector plate. The height of the collector plate was adjusted to the required distance before the electrospinning process was started. Lengths tested were 5 and $10 \mathrm{~cm}$.

\section{Flow Rate of Polymer-Solvent Solution}

The polymer-solvent solution was transferred to a $50 \mathrm{ml}$ syringe (BD Plastipak) and placed within the syringe pump (SP230IW2-World Precision Instruments). The flow rates applied during electrospinning were 0.05 and $0.1 \mathrm{ml} / \mathrm{min}$.

\section{Applied Electrospinning Parameter Summary}

Solutions of PCL in acetone with different concentrations were electrospun under different spinning parameters ranging from $\mathrm{A}$ to $\mathrm{H}$, as summarised in Table 1. Each spinning parameter was tested in triplicate $(n=3)$.

\section{Electrospun Fibre Analysis}

The stationary collector plate was covered in aluminium foil to allow easy removal of the deposited fibres whilst maintaining their structural integrity. Randomly selected areas of the fibre covered foil were cut into squares and mounted onto carbon coated stubs (Agar Scientific) and gold sputter-coated for a total of 2 min (Edwards Sputter Coater-S150B). Assessment of the electrospun samples was determined by Scanning Electron Microscopy (SEM) using a Topcon SM300 set to $8 \mathrm{~mm}$ working distance and $5 \mathrm{keV}$ accelerating voltage. Fibre diameters were analysed using Image tool for Windows (version 3.00). The scale bar on the SEM micrograph was calibrated for every micrograph prior to measuring fibre diameter. All spinning parameters were tested in triplicate and 100 fibres per SEM micrograph were measured.

\section{Statistical Analysis}

Statistical analysis of the measured fibres was performed using Graphpad Prism version 3.03 (Graphpad software). A Shapiro-Wilk test was performed to determine whether the measured data sets followed a Normal distribution. All data sets were normally distributed and were subsequently analysed by one-way ANOVA with Bonferroni post-tests (confidence level $95 \%$ ).

\section{Results and Discussion}

Comparison of electrospinning parameters, including; solution flow-rate, applied voltage, distance between needle-tip to collector plate and solution concentration were investigated for a sustainable polymer/solvent combination. Being a multi-variable technique, changing more than one parameter at any one time should have a greater effect on fibre diameter and morphology compared to changing just one parameter.

Irrespective of the parameters applied to the polymeric solutions, the SEM micrographs highlight an obvious variation in fibre formation and morphology depending on the initial polymer concentration (Figs. 2, 3). The micrographs, for concentrations 5 and $7.5 \% \mathrm{w} / \mathrm{v}$, demonstrate the presence of considerable beading amongst the fibres regardless of the spinning parameter combination applied. Yet when the polymer concentration was increased to $10 \% \mathrm{w} / \mathrm{v}$, SEM micrographs demonstrated no beading; however, the diameter of these bead-free fibres are visibly wider in comparison to the lower two concentrations. This would suggest the solution concentration is of over-riding importance in the formation of single, bead-free fibres and a concentration of $10 \% \mathrm{w} / \mathrm{v}$ appears to allow sufficient interaction between the solvent molecules and polymer chains with smooth, bead-free fibres resulting.

Compared to the other solution concentrations, the micrographs for $10 \% \mathrm{w} / \mathrm{v}$ show the fibres to be more varied as a consequence of applying different parameters. In particular, when the $10 \% \mathrm{w} / \mathrm{v}$ PCL/acetone solution was electrospun under baseline conditions (parameter combination A) $-0.1 \mathrm{ml} / \mathrm{min}, 15 \mathrm{kV}$ and $5 \mathrm{~cm}$-resultant fibres appeared to be flattened and 'wet'; however, when the 
Table 1 Electrospinning

parameters; solution flow-rate,

voltage and distance between needle-tip to collector, applied for poly( $\varepsilon$-caprolactone) (PCL) solutions with concentrations 5 ,

7.5 and $10 \% \mathrm{w} / \mathrm{v}$

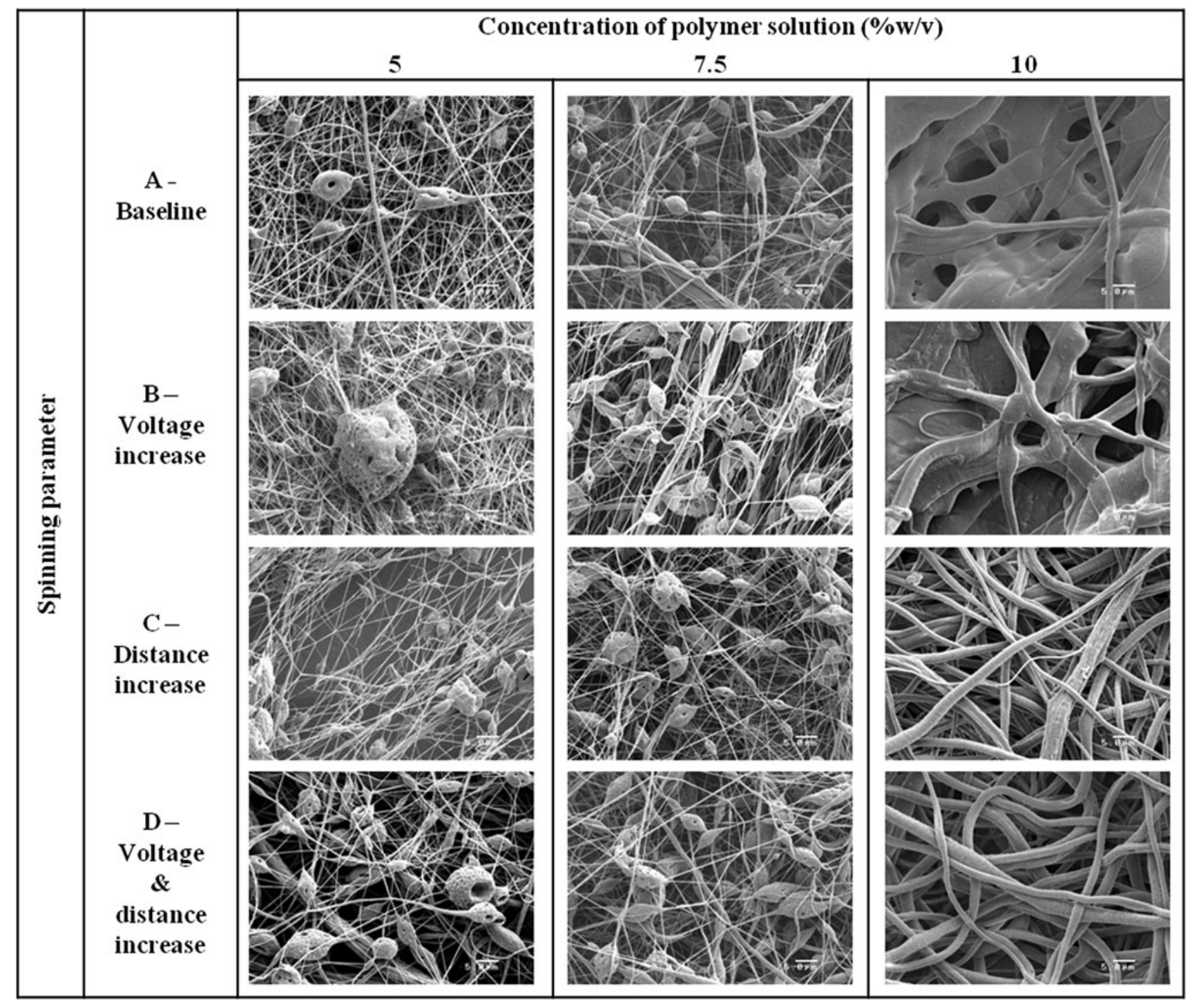

Fig. 2 SEM micrographs for concentrations, 5, 7.5 and $10 \% \mathrm{w} / \mathrm{v}$ when electrospun under spinning parameters a-d with high flow-rate $(0.1 \mathrm{ml} /$

$\min$ ). a Baseline, $\mathbf{b}$ increase in voltage, $\mathbf{c}$ increase in distance, $\mathbf{d}$ increase in both voltage and distance. (Magnification $\times 2,000$; scale-bar $5 \mu \mathrm{m}$ )

\begin{tabular}{|c|c|c|c|}
\hline \multirow{2}{*}{$\begin{array}{l}\text { Spinning parameter } \\
\text { combination }\end{array}$} & \multicolumn{3}{|c|}{ Spinning parameters } \\
\hline & $\begin{array}{l}\text { Flow rate } \\
(\mathrm{ml} / \mathrm{min})\end{array}$ & $\begin{array}{l}\text { Voltage } \\
(\mathrm{kV})\end{array}$ & $\begin{array}{l}\text { Needle tip to collector } \\
\text { distance }(\mathrm{cm})\end{array}$ \\
\hline $\mathbf{A}$ & 0.1 & 15 & 5 \\
\hline B & 0.1 & 25 & 5 \\
\hline C & 0.1 & 15 & 10 \\
\hline D & 0.1 & 25 & 10 \\
\hline $\mathbf{E}$ & 0.05 & 15 & 5 \\
\hline $\mathbf{F}$ & 0.05 & 25 & 5 \\
\hline $\mathbf{G}$ & 0.05 & 15 & 10 \\
\hline $\mathbf{H}$ & 0.05 & 25 & 10 \\
\hline
\end{tabular}




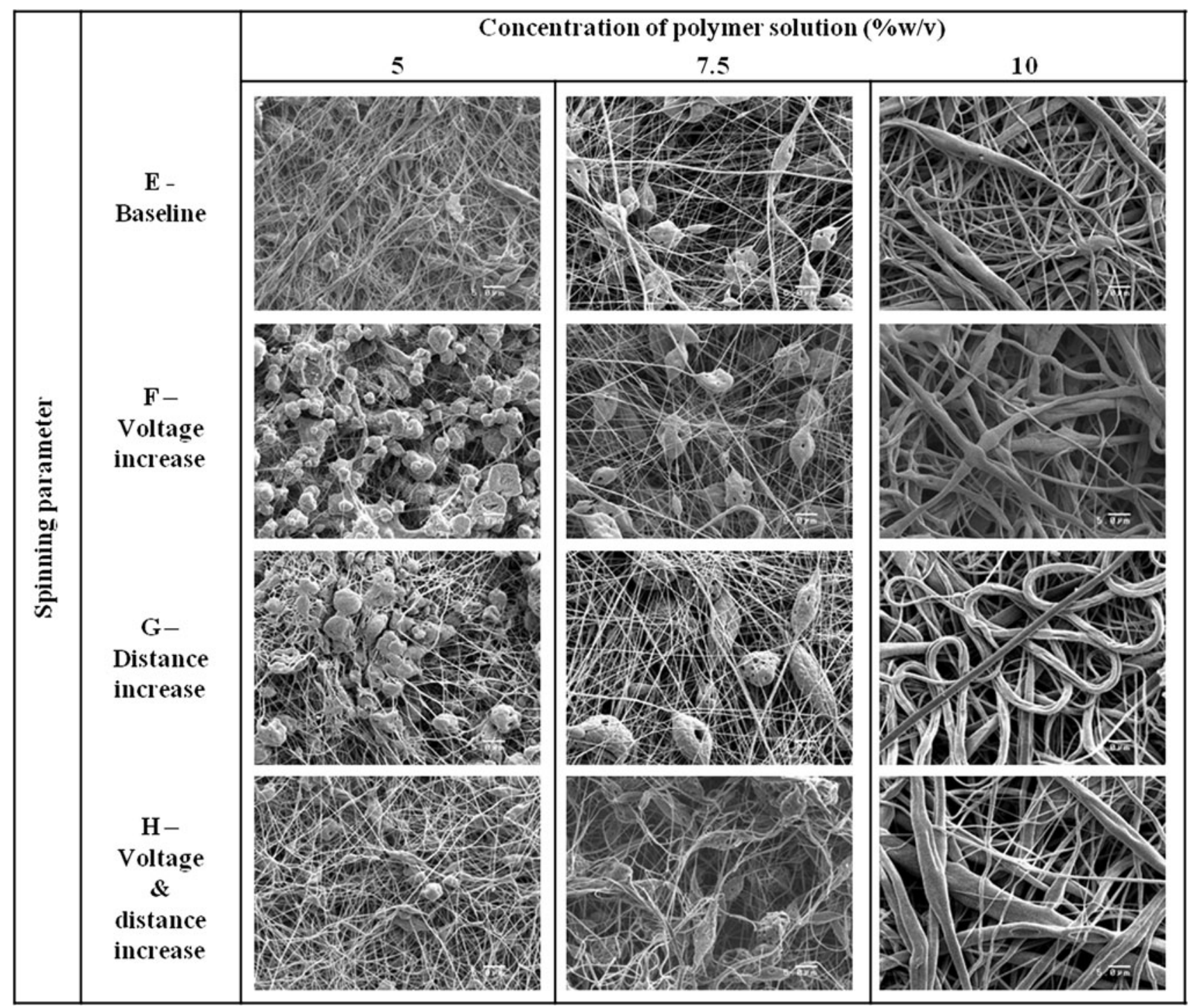

Fig. 3 SEM micrographs for concentrations, 5, 7.5 and $10 \% \mathrm{w} / \mathrm{v}$ when electrospun under spinning parameters a-d with low flow-rate $(0.05 \mathrm{ml} /$ $\mathrm{min}$ ). $\mathbf{e}$ Baseline, $\mathbf{f}$ increase in voltage, $\mathbf{g}$ increase in distance and $\mathbf{h}$ increase in both voltage and distance. (Magnification $\times 2,000$; scale-bar $5 \mu \mathrm{m}$ )

distance to the collector was increased to $10 \mathrm{~cm}$ the fibres were more rounded and uniform in morphology.

Measurement of fibre diameter for each spinning parameter combination was collated and divided into six studies as shown in Fig. 4. For the three concentrations investigated, the lower two concentrations (5 and $7.5 \%$ w/ v) resulted in the production of submicron fibres, whereas micron sized fibres were most common for $10 \% \mathrm{w} / \mathrm{v}$ solutions. There was no obvious trend for any of the concentrations or parameters investigated, though comparison of flow-rate for the baseline data demonstrated an overall increase in fibre diameter when the flow-rate was doubled, which was most apparent for fibres produced from $10 \% \mathrm{w} /$ $\mathrm{v}$ solutions, and is in agreement with a study by Zong et al. [32] on poly(lactic acid) electrospun fibres. An overall increase in fibre diameter was to be expected, as raising the flow-rate increased the volume of solution available to the electrospinning system, and may have reduced the time for solvent evaporation and adequate stretching of the polymer jet prior to impacting on the collector plate.

For $5 \% \mathrm{w} / \mathrm{v}$ with faster flow-rate, increasing the applied voltage had no significant effect on fibre diameter (Fig. 4a). However, doubling the distance between the needle-tip to the collector plate resulted in a considerable decrease in fibre diameter; and increasing both the voltage and distance led to a reduction in fibre diameter, though slightly higher compared to increased distance alone. This would suggest, for this particular solution concentration, the change in distance had a significant effect on final fibre diameter. Increasing the distance encouraged collection of 


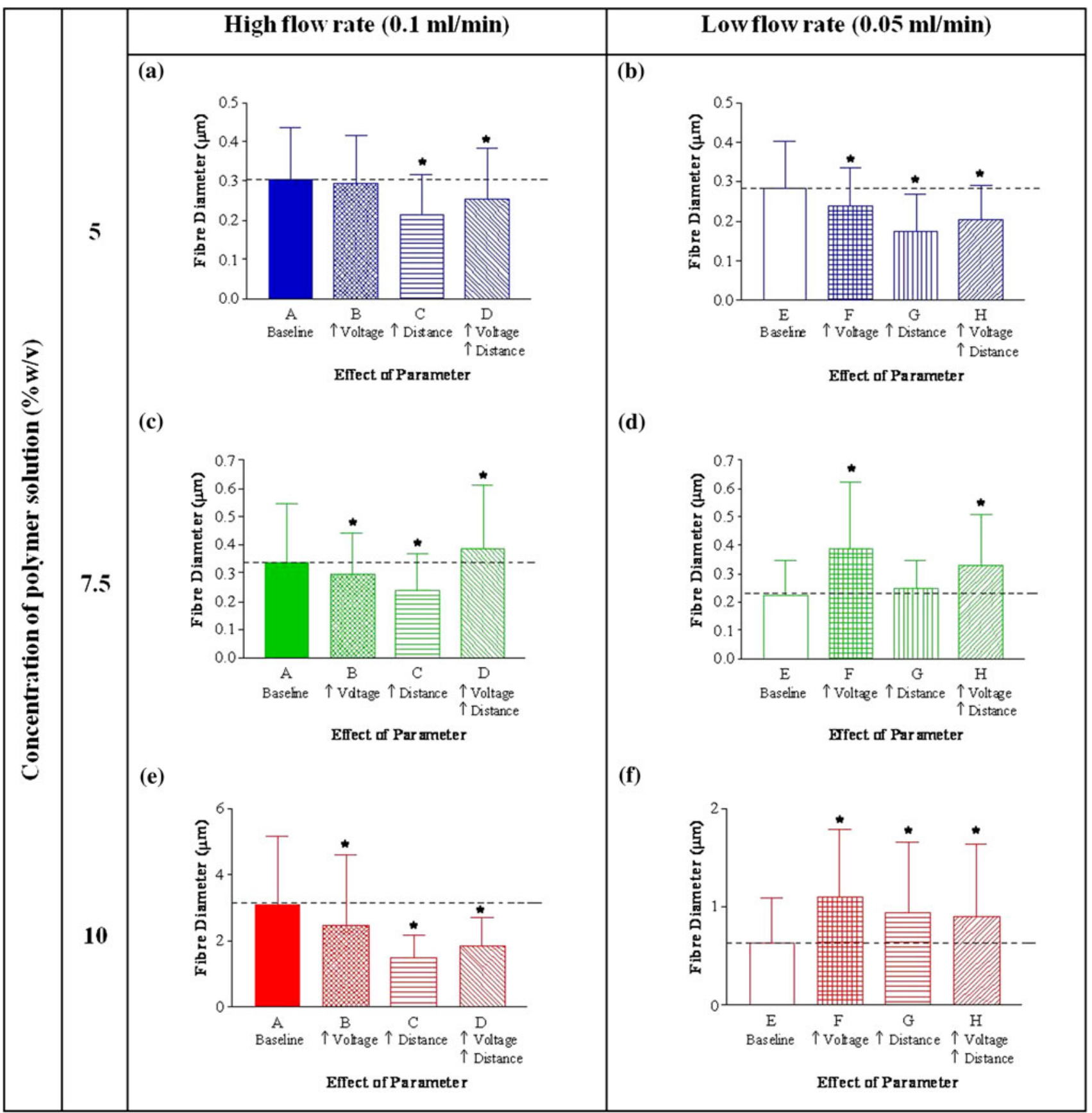

Fig. 4 Alteration of multiple spinning parameters at any one time and their effects on fibre diameter for three different solution concentrations $(5,7.5$ and $10 \% \mathrm{w} / \mathrm{v}$ poly( $\varepsilon$-caprolactone) in acetone).

finer fibres as the polymer jet had further distance to travel prior to impact, which allowed for greater solvent evaporation and thinning/stretching due to charge repulsion within the emitted jet. This observation is in agreement with Ayutsede et al. [33], whereby the diameter of electrospun silk fibroin fibres decreased by approximately $25 \mathrm{~nm}$ after doubling the distance from 5 to $10 \mathrm{~cm}$. For the same solution concentration spun under a slower flow-rate
One-way ANOVA with Bonferroni post-tests $(* p<0.05)(n=100$ fibres per spinning parameter). Dotted lines represent the mean baseline fibre diameter

$(0.05 \mathrm{ml} / \mathrm{min})$, increases in voltage, distance, and voltage and distance together, resulted in significant decreases in fibre diameter and again this was most noticeable for increased distance alone (Fig. 4b).

Solution concentration, $7.5 \% \mathrm{w} / \mathrm{v}$, when pumped with a faster flow-rate the mean fibre diameter was 0.34 $( \pm 0.21) \mu \mathrm{m}$ (Fig. 4c). Separately increasing the voltage and distance caused a significant decrease in mean fibre 
diameter. However, when increasing the voltage and distance together, the mean fibre diameter was higher than the baseline diameter. In contrast, spinning the $7.5 \% \mathrm{w} / \mathrm{v}$ solution with a slower flow-rate resulted in an increase in fibre diameter for higher voltage and voltage-distance in combination (Fig. 4d). No significant difference in mean diameter was observed when distance alone was doubled, although there was a slight increase in fibre diameter when spinning over a $10 \mathrm{~cm}$ distance. The results for this solution concentration do not support the literature; whereby previous research studies have shown that an increase in applied voltage results in the formation of finer diameter fibres due to increased levels of charge repulsion causing significant stretching and thinning of the polymer jet as it travels through the electric field [34], whilst the increased acceleration of the jet speeds up solvent evaporation resulting in drier and more defined fibres [35]. However, a more recent paper by Tong and Wang [36] proposes a higher voltage could affect the final fibre diameter in two different ways - thicker diameter fibres could result from the polymer jet being initially larger, or thinner fibres may be produced as greater electric forces allows for more effective stretching of the jet. Tong and Wang go on to suggest that these two effects may cancel each other out and consequently the influence of varying the applied voltage is reduced. It can be speculated that for this concentration $(7.5 \% \mathrm{w} / \mathrm{v})$ the over-riding cause for the obtained results is the effect of increasing voltage applied to the system. Acceleration of the jet may have been too great for the distance allowed to accommodate sufficient stretching and thinning prior to contact with the collector plate had a distance greater than $10 \mathrm{~cm}$ been applied, finer fibres may have resulted.

With faster flow-rate, the mean fibre diameter for solutions of $10 \% \mathrm{w} / \mathrm{v}$ concentration reduced significantly for all spinning parameter variations (Fig. 4e). This was most noticeable when doubling the distance and suggests the air gap $(10 \mathrm{~cm})$ was more than sufficient to allow thinning of the polymer jet prior to impact. Conversely, the reverse was observed when a slower flow-rate was incorporated (Fig. 4f); where the initial baseline fibre diameter was submicron $(0.64 \mu \mathrm{m})$, however, upon increasing the voltage, distance and voltage-distance combined, the mean fibre diameter was significantly increased being approximately $1 \mu \mathrm{m}$ in all three cases. This was a similar observation as for $7.5 \% \mathrm{w} / \mathrm{v}$ electrospun with low flow-rate.

Collectively, increasing the voltage from 15 to $25 \mathrm{kV}$ resulted in an overall reduction in fibre diameter for four out of the six studies, suggesting the increased acceleration of the polymer jet was sufficient to cause further charge repulsion and subsequent thinning, whilst also speeding the rate of solvent evaporation-this was most noticeable from the SEM micrographs for $10 \% \mathrm{w} / \mathrm{v}$, Baseline (A) and
Voltage increase (B) (Fig. 2), where comparison between the two images shows the fibres to be flat and 'wet', and with increased voltage fibres become more rounded and 'solvent-free'. Similarly, increasing the distance alone from 5 to $10 \mathrm{~cm}$ resulted in the fibre diameter being significantly decreased in two-thirds of the studies examined. This would imply that doubling the distance allowed greater time for additional thinning and stretching of the polymer jet as it travelled towards the collector plate.

The twin aims of this study were to ascertain whether fibres could be formed by electrospinning PCL dissolved in acetone - a readily available and non-toxic solvent, and to investigate the effects of varying more than one spinning parameter at any one time for this polymer/solvent system. Overall, PCL dissolved in acetone was readily electrospun with varying parameters. It was clear that the effect on final fibre diameter and morphology when altering just one parameter was not reproduced when another parameter was altered simultaneously. For this investigation, when increasing both the voltage and distance together, the mean fibre diameter was only reduced in half of all studies and this reduction was never below the mean fibre diameter when the distance alone was doubled. This would suggest the increased voltage is having an overriding effect on the emitted polymer jet and an air-gap distance greater than $10 \mathrm{~cm}$ may be necessary to further reduce fibre diameter by increasing the time for stretching and thinning of this jet.

These findings imply that a greater distance from needle-tip to collector plate results in finer diameter fibres. Reduced flow-rates yielded thinner fibres for all three concentrations studied. Change in voltage was met with a mixed effect on fibre diameter, suggesting the two voltages tested affected the polymer jet with similar levels of stretching and time for solvent evaporation. Solutions of different concentrations produced a range of fibre diameters and morphologies. Fibres from lower concentrations were submicron in diameter but riddled with beads, whereas a higher concentration resulted in a significant reduction in bead formation; suggesting an ideal interaction between the polymer chains and solvent molecules. However, reducing bead formation comes at a cost to fibre diameter. Increasing the quantity of polymer in solution caused a significant increase in fibre diameter, with mean values being of micron dimensions.

\section{Conclusion}

This investigation has demonstrated the ability to electrospin synthetic PCL using a sustainable and less toxic and hazardous solvent (acetone). Investigation of varying parameters yielded trends near identical to those already documented in the literature for more harmful solvents, 
which indicates acetone to be a reliable electrospinning solvent and should be given greater consideration when selecting and creating future polymer/solvent systems.

Acknowledgments This work was funded by the Engineering and Physical Sciences Research Council (EPSRC).

\section{References}

1. Zhou Y, Frietag M, Hone J, Staii C, Johnson AT, Pinto NJ et al (2003) Fabrication and electrical characterization of polyanilinebased nanofibers with diameter below $30 \mathrm{~nm}$. Appl Phys Lett 83(18):3800-3802

2. Taylor G (1964) Disintegration of water drops in an electric field. Proc R Soc Lond Ser A 280(1382):383-397

3. Doshi J, Reneker DH (1995) Electrospinning process and applications of electrospun fibers. J Electrostat 35(2-3):151-160

4. Kenawy E-R, Bowlin GL, Mansfield K, Layman J, Simpson DG, Sanders EH et al (2005) Release of tetracycline hydrochloride from electrospun poly(ethylene-co-vinylacetate), poly(lactic acid), and a blend. J Control Release 81(1-2):57-64

5. Tan S-H, Inai R, Kotaki M, Ramakrishna S (2005) Systematic parameter study for ultra-fine fiber fabrication via electrospinning process. Polymer 46(16):6128-6134

6. Kwon IK, Kidoaki S, Matsuda T (2005) Electrospun nano- to microfiber fabrics made of biodegradable copolyesters: structural characteristics, mechanical properties and cell adhesion potential. Biomaterials 26(18):3929-3939

7. Browning E (1959) Toxic solvents: a review. Br J Ind Med $16(1): 23-39$

8. Kumbar SG, James R, Nukavarapu SP, Laurencin CT (2008) Electrospun nanofiber scaffolds: engineering soft tissues. Biomed Mater 3(3):034002

9. George HA, Johnson JL, Moore WE, Holdeman LV, Chen JS (1983) Acetone, isopropanol, and butanol production by Clostridium beijerinckii (syn. Clostridium butylicum) and Clostridium aurantibutyricum. Appl Environ Microbiol 45:1160-1163

10. Hanai T, Atsumi S, Liao JC (2007) Engineered synthetic pathway for isopropanol production in Escherichia coli. Appl Environ Microbiol 73:7814-7818

11. Martins A, Pinho ED, Vítor MC, Faria S, Marques AP, Reis RL et al (2010) Biodegradable nanofibers-reinforced microfibrous composite scaffolds for bone tissue engineering. Tissue Eng Part A 16(12):3599-3609

12. Zhao L, He C, Zhang D, Chang J, Cui L (2009) Comparison of electrospun PBSU and PLGA scaffolds applied in vascular tissue engineering. J Biomim Biomater Tissue Eng 2:27-38

13. Homaeigohar SSh, Buhr K, Ebert K (2010) Polyethersulfone electrospun nanofibrous composite membrane for liquid filtration. J Membr Sci 365(1-2):68-77

14. Yun KM, Suryamas AB, Iskandar F, Bao L, Niinuma H, Okuyama K (2010) Morphology optimization of polymer nanofiber for applications in aerosol particle filtration. Sep Purif Technol 75(3):340-345

15. Sundarrajan S, Murugan R, Nair AS, Ramakrishna S (2010) Fabrication of P3HT/PCBM solar cloth by electrospinning technique. Mater Lett 64(21):2369-2372

16. Tamura T, Kawakami H (2010) Aligned electrospun nanofiber composite membranes for fuel cell electrolytes. Nano Lett 10(4):1324-1328

17. Pham QP, Sharma U, Mikos AG (2006) Electrospinning of polymeric nanofibers for tissue engineering applications: a review. Tissue Eng 12(5):1197-1211
18. Bosworth L, Downes S (2009) Biocompatible three-dimensional scaffolds for tendon tissue engineering using electrospinning. In: Di Silvio L (ed) Cellular response to biomaterials. Woodhead, Cambridge

19. Zong X, Bien H, Chung C-Y, Yin L, Fang D, Hsiao BS et al (2005) Electrospun fine-textured scaffolds for heart tissue constructs. Biomaterials 26(26):5330-5338

20. Shim IK, Jung MR, Kim KH, Seol YJ, Park YJ, Park WH et al (2010) Novel three-dimensional scaffolds of poly(L-lactic acid) microfibers using electrospinning and mechanical expansion: fabrication and bone regeneration. J Biomed Mater Res B Appl Biomater 95B(1):150-160

21. Jha BS, Colello RJ, Bowman JR, Sell SA, Lee KD, Bigbee JW et al (2011) Two pole air gap electrospinning: fabrication of highly aligned, three-dimensional scaffolds for nerve reconstruction. Acta Biomater 7(1):203-215

22. Ghasemi-Mobarakeh L, Prabhakaran MP, Morshed M, NasrEsfahani M-H, Ramakrishna S (2008) Electrospun poly( $\varepsilon$-caprolactone)/gelatin nanofibrous scaffolds for nerve tissue engineering. Biomaterials 29(34):4532-4539

23. Bosworth L, Clegg P, Downes S (2008) Electrospun nanofibres of polycaprolactone, and their use for tendon regeneration. Int $\mathrm{J}$ Nano Biomater 1(3):263-279

24. Zamarripa N, Farboodmanesh S, Kuo CK (2009) Novel biomimetic scaffold for tendon and ligament tissue engineering. Bioengineering conference, 2009 IEEE 35th annual northeast

25. Powell HM, Boyce ST (2009) Engineered human skin fabricated using electrospun collagen-PCL blends: morphogenesis and mechanical properties. Tissue Eng Part A 15(8):2177-2187

26. Chen H, Huang J, Yu J, Liu S, Gu P (2011) Electrospun chitosangraft-poly ( $\varepsilon$-caprolactone)/poly ( $\varepsilon$-caprolactone) cationic nanofibrous mats as potential scaffolds for skin tissue engineering. Int J Biol Macromol 48(1):13-19

27. Erisken C, Kalyon DM, Wang H (2008) Functionally graded electrospun polycaprolactone and $\beta$-tricalcium phosphate nanocomposites for tissue engineering applications. Biomaterials 29(30):4065-4073

28. Yang F, Wolke JGC, Jansen JA (2008) Biomimetic calcium phosphate coating on electrospun poly( $\varepsilon$-caprolactone) scaffolds for bone tissue engineering. Chem Eng J 137(1):154-161

29. Nam J, Huang Y, Agarwal S, Lannutti J (2008) Materials selection and residual solvent retention in biodegradable electrospun fibers. J Appl Polym Sci 107(3):1547-1554

30. Jarusuwannapoom $\mathrm{T}$, Hongrojjanawiwat $\mathrm{W}$, Jitjaicham $\mathrm{S}$, Wannatong L, Nithitanakul M, Pattamaprom C et al (2005) Effect of solvents on electro-spinnability of polystyrene solutions and morphological appearance of resulting electrospun polystyrene fibers. Eur Polymer J 41(3):409-421

31. Heikkilä P, Harlin A (2008) Parameter study of electrospinning of polyamide-6. Eur Polymer J 44(10):3067-3079

32. Zong X, Kim K, Fang D, Ran S, Hsiao BS, Chu B (2002) Structure and process relationship of electrospun nanofiber membranes. Polymer 43(16):4403-4412

33. Ayutsede J, Gandhi M, Sukigara S, Micklus M, Chen H-E, Ko F (2005) Regeneration of bombyx mori silk by electrospinning. Part 3: characterization of electrospun nonwoven mat. Polymer 46(5):1625-1634

34. Lee JS, Choi KH, Ghim HD, Kim SS, Chun DH, Kim HY et al (2004) Role of molecular weight of atactic poly(vinyl alcohol) (PVA) in the structure and properties of PVA nanofabric prepared by electrospinning. J Appl Polym Sci 93(4):1638-1646

35. Pawlowski KJ, Belvin HL, Raney DL, Su J, Harrison JS, Siochi EJ (2003) Electrospinning of a micro-air vehicle wing skin. Polymer 44(4):1309-1314

36. Tong H-W, Wang M (2011) An investigation into the influence of electrospinning parameters on the diameter and alignment of poly(hydroxybutyrate-co-hydroxyvalerate) fibers. J Appl Polym Sci 120(3):1694-1706 